\title{
Language and Communication in Mathematics Education
}

\author{
Tracy Craig and Candia Morgan
}

\section{Introduction}

The topic of "Language and Communication in Mathematics Education" covers a wide range of areas of interest, ranging from the question of what constitutes "language" in mathematics, through investigations of communicative interactions in mathematics classrooms and study of issues involved in teaching and learning mathematics in multilingual settings. This breadth was well represented in the papers accepted for presentation in the Topic Study Group at ICME12. In order to facilitate discussion, the paper presentations in each session were divided into two sets, with participants choosing which set to attend. This allowed the discussion to focus in greater depth on common themes. In addition, one session of the TSG was devoted to a panel discussion on the topic of "Theoretical and methodological issues in studying language in mathematics education" and a final plenary meeting enabled participants to reflect on the TSG as a whole, the common issues addressed, the lessons learnt and aspirations for future work on the topic. In this report, we present an overview of the major themes arising in the papers presented and in the discussions during the congress.

Organizers Co-chairs: Tracy Craig (South Africa), Candia Morgan (UK); Team Members: Marcus Schuette (Germany), Rae Young Kim (Korea), David Wagner (Canada); Liaison IPC Member: Oh Nam Kwon (Korea).

\footnotetext{
T. Craig $(\bowtie)$

University of Cape Town, Cape Town, South Africa

e-mail: tracy.craig@uct.ac.za

C. Morgan

Institute of Education, University of London, London, UK

e-mail: c.morgan@ioe.ac.uk

(C) The Author(s) 2015 


\section{Classroom Interactions}

The nature of classroom interactions and their relationship to the doing and learning of mathematics is a major area of research, forming the focus of many of the papers presented in the TSG. The majority of these papers were concerned with the construction of mathematics and mathematical thinking and, in particular, the ways that teachers and teaching methods shape the possibilities for students' mathematical thinking and the ways in which mathematical knowledge is developed in interactions between teacher and students and among groups of students.

Drageset characterised different ways in which teachers respond to student contributions, offering a framework for analysing how different practices may have potential to help student thinking to progress. Milani also discussed how different forms of interaction may relate to learning, identifying dialogic questioning as a form that involves students as active participants in the learning process. Focusing on the development of spatial perception in young children, Schuette's study investigated the different ways in which this domain is talked about in the three contexts of primary school, infant school and in the home. Park used a semiotic approach to analyse and describe students' proportional reasoning, finding that multiplicative strategies were more successful than either additive or formal strategies.

Lee et al. looked at the effects of using "story-telling" instead of formal proof when teaching about transformation of functions, suggesting that students have similar success with both methods but that the story-telling approach has affective benefits. Investigating students' ability to present their solution methods and explanations in writing, Misono and Takeda identified a need for teachers to work with students to develop their use of mathematical language and their communication skills. Another approach to thinking about teaching methods was provided by O'Keefe and O'Donoghue, who offered a linguistic analysis of textbooks, using this to characterise how the nature of mathematics is portrayed.

Looking in detail at a teacher working with a small group of children, Gellert analysed an episode in which a disagreement arises, identifying the epistemological development and how the teacher and students negotiate mathematically. In Barcelona, a group of researchers is investigating classroom interaction from the point of view of studying the social construction of mathematical knowledge. This group presented two papers looking deeply at the mathematical activity of students when working in pairs (Badillo, Planas, Goizueta and Manrique) and in whole group discussion (Chico, Planas and Goizueta).

Language is not only used for communicating knowledge but is also a means for establishing our identities and relationships. This function of language was addressed by Heyd-Metzuyanim, whose paper presented an analysis of the "identifying" and "mathematizing" interactions in two small groups of students while they were engaged in problem solving. She suggested that, for the lower attaining group, the struggles over identification may have hindered their progress in learning. 


\section{Multilingualism in Mathematics Education}

There has been a longstanding interest in the issues involved in teaching and learning mathematics in different languages. This originated to a large extent in the context of post-colonialism at a time when many countries with a legacy of education in the language of the ex-colonial power were struggling to value their own national and local languages and to develop the use of these languages in education. Political struggles over choice of language of instruction continue, while research is adding to our understanding of how characteristics of specific languages may affect the nature of the mathematics that is done using the language as well as how they may affect student learning. Two papers by Edmonds-Wathen and by Russell and Chernoff both addressed the differences between Aboriginal Englishes, spoken in indigenous communities in Australia and Canada respectively, and the standard forms of English spoken by the majority of their teachers and used in the classroom. While appearing similar in some respects, these languages carry different cultural and conceptual underpinnings with consequent possibilities for meaning making that teachers need to be aware of.

With increased mobility of populations as well as national decisions to offer mathematics education in a range of languages, mathematics educators across the world are increasingly needing to deal with classrooms in which students speak more than one language and have varying levels of competence in the main language of instruction. While this is often portrayed as being a 'problem', the papers presented in the TSG demonstrate that mathematics educators are dealing in subtle and important ways with the complex issues involved. Indeed, the research reported by Ní Ríordáin and McClusky from Ireland indicates that bilingual students with good competence in both languages (Irish and English) outperformed those for whom one language was dominant. Investigation of the students' language use while problem solving suggested that bilingualism was associated with enhanced metacognitive ability. The benefits of bilingualism are one of the motivations behind the introduction of Content and Language Integrated Learning (CLIL), a policy supported by the European Commission, involving teaching curriculum content through the medium of a foreign language. Maffei, Favilli and Peroni reported on the introduction of CLIL in Italy, teaching mathematics through the medium of English in secondary schools.

Whereas the students investigated by Ní Ríordáin and McClusky and by Maffei et al. experienced teaching and learning in both languages, Craig's study looked at the experience of university students in South Africa, studying mathematics through the medium of English only, in spite of the fact that for some of them this was not their main language. She introduced writing activities into the classroom as a means of developing students' understanding of mathematical concepts and found that both English and non-English main language students grappled similarly with the mathematical content but that language was a source of difficulty and a potential obstacle for less well-prepared students. The question of how pedagogic methods may have differential effects for students from different linguistic and cultural 
backgrounds was also addressed by the study proposed by Björklund Boistrop and Norén. Their concern was to investigate teachers' assessment practices in interactions with students in multilingual classrooms in Sweden.

\section{Theory and Methodology}

A wide range of theoretical perspectives and methodologies was apparent in the papers presented and this was a focus of much discussion during the TSG sessions as participants sought to understand the basis for analyses and conclusions and to interrogate and develop the rigour of the methods used to study language and communication. Two presentations took as their main topic the use and development of theory and methodology. Nachlielli and Tabach addressed the combination of two theories: the social semiotics and Systemic Functional Linguistics of Halliday (1974), a general semiotic and linguistic theory, and Sfard's theory of commognition (2008), which addresses the nature of mathematical discourse specifically. They used these theories to develop a framework for analysing classroom interaction. Similarly, Tang, Morgan and Sfard drew on the same two theories to present the development of an analytical framework for studying examination papers and the nature of the mathematical activity that students taking these examinations are expected to engage in.

Given the widespread interest in theory and methodology among those attending the TSG, a plenary panel discussion on this topic was organised. Three presenters, Einat Heyd-Metzuyanim, Candia Morgan and Máire Ní Ríordáin were asked to identify and reflect upon the theoretical and methodological issues that had arisen for them in their research programmes, the choices they had made and the ways these choices may have affected the outcomes of the study. The presenters also questioned each other and responded to these questions and to those raised by other members of the TSG. Issues raised included the definition and operationalization of constructs, use of quantitative and qualitative methods, and the effects of language used by a researcher on the nature of data collected.

\section{Final Reflections}

Underpinning many of the presentations were the intertwined themes of politics and culture. It was repeatedly observed that language in education is inherently political, in more than one way. National or cultural politics can influence the choice of language and teaching methods, the roles language plays in the classroom, researcher access to classrooms and the uses to which research findings are put. Language is similarly influenced by culture and is an indicator of cultural identity. Politics, culture, language and teaching and learning are interrelated. Additionally, culture can influence research methodology. 
Language, from the point of view of the learner, both gives and limits access to mathematics. Communicative activities in and outside the classroom shape mathematical thinking and thus language mediates access to mathematics. From the point of view of the researcher, language is both a research tool and a focus for research into mathematics teaching and learning. There is a relationship between language and learning, but also one between language and pedagogy. Analysis of communicative activities in the context of mathematics teaching and learning allows us to understand both. For successful learning to occur the teacher needs to effectively communicate mathematics, bringing issues such as open and closed discourses, specialised and everyday registers, multimodality and multilingualism to the attention of the researcher of language.

The practical topics of data collection, processing and analysis were of particular interest. Analysing language issues in the mathematics classroom can be difficult, there are methodological dilemmas and challenges. The logistics of gathering and analysing language data can benefit from further investigation, addressing issues such as how to analyse large corpuses of data when the method of analysis calls for detailed attention to small amounts of text. Large bodies of language data could benefit from being made accessible to large groups of people to work collaboratively, but that in itself brings in complications of ethics and multiple languages. Also, context is key to understanding and, in data sharing, the context of the data collection could be obscured. The role of language in the communication of mathematics is complex; in trying to capture that complexity we tend to reduce it for ease of understanding. This introduces a tension for researchers as something is inevitably lost in that reduction. Analysis of language as communication of mathematics benefits from the insights offered by cross-disciplinary perspectives, such as from linguistics.

The Topic Study Group closed with an appreciation of the small community which had formed at ICME, a hope to collaborate (and data share?) in future and a call to pool our skills and knowledge with one another.

Open Access This chapter is distributed under the terms of the Creative Commons Attribution Noncommercial License, which permits any noncommercial use, distribution, and reproduction in any medium, provided the original author(s) and source are credited.

\section{References}

Halliday, M. A. K. (1974). Some aspects of sociolinguistics Interactions between linguistics and mathematical education symposium. Paris: UNESCO.

Sfard, A. (2008). Thinking as Communicating: Human Development, the Growth of Discourses, and Mathematizing. Cambridge: Cambridge University Press. 